\title{
Minimizing the Total Annualized Cost of “SIDEM” seawater desalination unit
}

\begin{abstract}
This paper presents a steady state analysis of a multi-effect thermal vapor compression desalination plant (MED-TVC) installed in the Tunisian Chemical Group (GCT) factory. A thermodynamic model includes mass and energy balances of the system are presented. An economic model is developed to estimate the cost of produced water $\left(\$ / \mathrm{m}^{3}\right)$. The proposed models to minimize the total annualized cost (TAC) of the desalination unit are based on a combination between the process simulator Aspen HYSYS and Matlab. The effects of the operating parameters variations on the system's performance were studied. The simulation results show a good agreement with the industrial data of the pilot unit.
\end{abstract}

Keywords: Steady state, multi-effect, thermal vapor compression, desalination, optimization.

\section{Introduction}

In the recent years the demand of pure water increases caused to the rapid population growth and the evolution of industrial applications. The International Desalination Association [1] reports that currently there are more than 18,000 desalination plants in operation worldwide, with a maximum production capacity of around 90 million cubic .meters per day $\left(\mathrm{m}^{3} / \mathrm{d}\right)$ of fresh water [1]. Desalination technologies can be divided in two categories: thermal and membranes systems. The process of Multi-effect distillation coupled with thermal vapor compressor (MEDTVC) is one of the most important thermal desalination units.

El-Dessouky and Ettouney [2] presented detailed mathematical and economic analysis for the thermal desalination plants (multi-stage flash (MSF), multi-effect distillation (MED), multieffect thermal vapor compression (MED-TVC) and multi-effect mechanical vapor compression (MED-MVC)). In literature, many studies [3-5] have been published about the applications of the first and the second laws of thermodynamics to analyze the MED-TVC systems. The models were based on mass, energy and exergy balances equations and the thermodynamics properties of seawater. 
The application of numerical simulation approach to study and optimize the MED-TVC and MSF desalination units presented in several papers as in [6-9]. In these works, authors presented several steady state and dynamics models using different software such as Aspen Custom Modeler, Computational Flow Dynamics (CFD), gPROMS simulator and discussed their simplicity and flexibility in order to modify inputs parameters, model correlations or process equipment as well as the economic evaluation.

Due to the development of thermal desalination technologies, recent researches focused on the optimization and parametric study of these plants. Several studies [10-12] investigated in the effect of operating conditions (i.e flow rate and temperature of feed seawater, steam temperature) and in the design conditions such as; number of effects, the scale thickness of the first effect and the condenser. They studied their influences on the production rate and the Gain output ratio (GOR) value on different industrial MED (with and without TVC) units and their simulation results were compared with models from literature. Kouhikamali et al. [13-14] studied the effect of the pressure drop of condensation inside tubes and evaporation outside tubes in the heat exchanger on the energy consumption. The influence of the length and diameter of tubes on the plant performance and the system costs were investigated. A work by Al-Mutaz et al. [15] describe the influence of changing the suction position of the thermal vapor compressor as well as the effect of suction pressure on the energy consumption and the specific heat transfer area of a MED-TVC plant.

An important works by Dahdah and Mitsos [16-17] present various new configurations combine thermal desalination with thermal compression systems. Authors focused on the location of a steam ejector to find the optimal design of hybrid MED-TVC-MSF system. Further, a multi-objective structural optimization is performed in which the GOR of the structures is maximized while the specific heat transfers area requirements (sA) are minimized using the General Algebraic Modeling System (GAMS) as the solver of the problem. On the other hand, Skiborowski et al. [18] optimized a superstructure of a reverse osmosis (RO) and a forward-feed MED hybrid system. They presented an optimization strategy using a non-linear program to obtain the optimal configuration.

Under the increasing price of oil and the high energy consumption of thermal plants, several researches [19-20] have been published on the thermo-economic optimizations of these systems. In literature, fewer studies are carried out on the multi-objective optimization (MOO) 
in order to minimize the total annualized cost (TAC) of desalination systems. Tanvir et al. [21] suggested a combination between gPROMS model and optimization routines to minimize the TAC of MSF plant. Druetta et al. [22] developed a nonlinear problem to determine the nominal optimal sizing of equipment and optimal operating conditions that satisfy a fixed nominal production of fresh water at minimum TAC for a MED unit. In this research, the equations were implemented in GAMS (General Solver Modeling System) and CONOPT was used as a NLP local solver. Esfahani et al. [23] proposed a MOO to minimize the .TAC, maximize the GOR and the product water flow rate for a MED-TVC system based on exergy analysis by using a genetic algorithm (GA).

In literature, published papers presented two ways to study and solve the different problems approaches for the MED-TVC systems; programming algorithms or several commercials process simulators. In contrast, this paper presents a new method to minimize the TAC of MED-TVC plant based on a combination between Matlab and the process simulator Aspen HYSYS. The mathematical and economic equations defining the unit are implemented in Matlab and the flowsheet of the unit is created with Aspen HYSYS. This approach can be applied in several problems such as the process design, the parametric study and the economic analysis.

The paper is organized as follows: Section 2 presents a brief description of the MED-TVC desalination unit. Section 3 and 4 describes the assumptions used to simplify the study, the mathematical and the economic models used to obtain the cost of produced water (in $\$ / \mathrm{m}^{3}$ ). The problem formulation and the proposed simulation-optimization are illustrated in section 5 with the decision variables and constraints. Section 6 then combines the results of simulations and a parametric study of several parameters. The last section is devoted to concluding remarks

\section{MED-TVC process description}

The desalination plant presented in this paper is an actual MED-TVC unit located in the Phosphoric Acid Plant owned by the GCT in the industrial area of Gabes (south of Tunisia). The GCT investigated in the thermal plants with different capacities in their industrials factories. The choice of this type of plant has many reasons: the need of pure water used in the production of phosphate and its derivatives, the availability of heating steam produced by the turbine and the factories locations near the sea. 
The presented unit manufactured by the French Company "SIDEM". It composed by three evaporators, a thermal vapor compressor and a condenser. A schematic of the SIDEM unit is shown in Fig. 1. The seawater enters in the tubes of down condenser (after treatment), its temperature increases a few degrees due to the condensation of an amount of steam, comes from the last effect, in the shell side. Then, the seawater flow rate is divided into two parts; the first part rejected to the sea called cooling water and the second is distributed equally between the effects. Thermal vapor compressor is used to compress the motive steam from the external source and entrain a part of vapor produced in the last effect. The compressed stream $\left(\mathrm{V}_{\mathrm{cv}}\right)$ enters in the tubes of the first effect. In each effect, the heat steam enters in the tubes and the feed seawater is sprayed with the nozzles located in the summit of the effect. Steam condenses inside into distillate which heats the feed seawater outside the tubes. Part of seawater evaporates and generates an amount of vapor, which passes to the tubes of the next effect as a heat source. The second part represents the rejected brine. This process is repeated for all effects. Brine and distillate are collected from effect to effect until the last one and finally are extracted by centrifugal pumps.

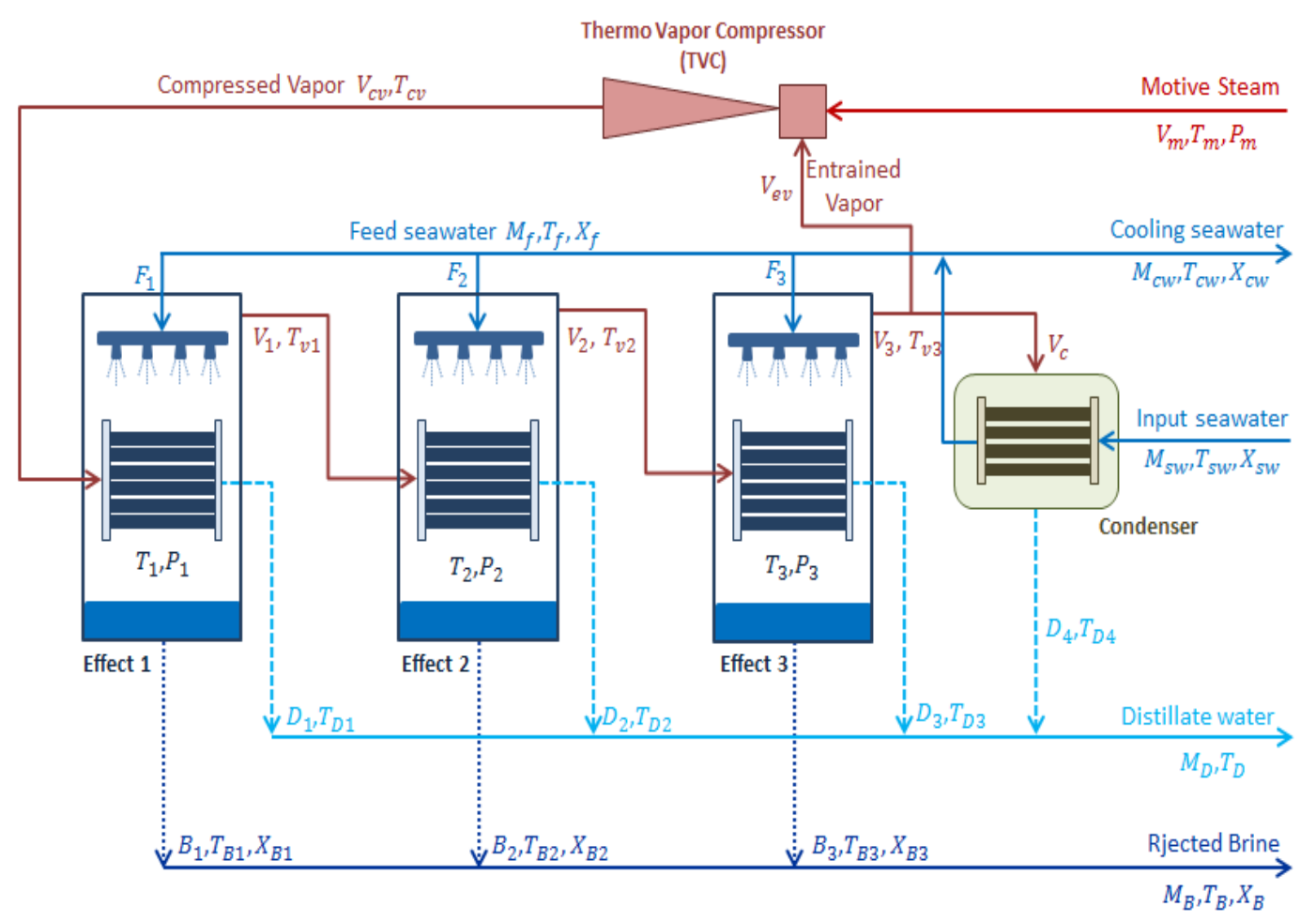

Fig. 1. Flow diagram of MED-TVC system (SIDEM unit).

\section{Assumptions and mathematical model}

\subsection{Assumptions}


In order to obtain a simple mathematical model, the following assumptions are considered:

- The desalination plant operates in steady state [19].

- Thermodynamics losses include just the boiling point elevation (BPE) [15].

- Pressure drops across the demister and during the condensation are neglected [22].

- The dimensions of each equipment; effects, compressor, condenser (length, width and height) are not included in the model [22].

- The distillate water and vapor formed in effect are free of salt [23-24].

- Heat losses from desalination to the surroundings are negligible because the system operates at low temperature (between 100 and $40^{\circ} \mathrm{C}$ [24]).

- Physical properties of seawater are taken as a function of temperature and salinity [2].

- To achieve the optimum operating conditions, temperature difference between all effects is assumed to be equal. $T_{1}$ and $T_{n}$ are the first and the last effect temperature respectively, the temperature difference can be expressed as [5, 25]:

$\Delta T=\frac{T_{1}-T_{n}}{n-1}$

Where $T_{1}$ and $T_{n}$ are defined as follow:

$T_{1}=T_{c v}-\Delta T$

$T_{i+1}=T_{i}-\Delta T, \quad i=2 \ldots n$

\subsection{Mathematical Model}

As mentioned earlier, Fig.1 shows a schematic diagram of the system with the configurations of streams. Fig. 2 shows the inlet and outlet streams of an effect of the desalination unit. The mathematical model based on the mass balances, the energy balances, the salt mass conservation law and the heat transfer equations. The model also includes correlations for estimating the heat transfer coefficients, thermodynamics losses and the physical properties of seawater. 


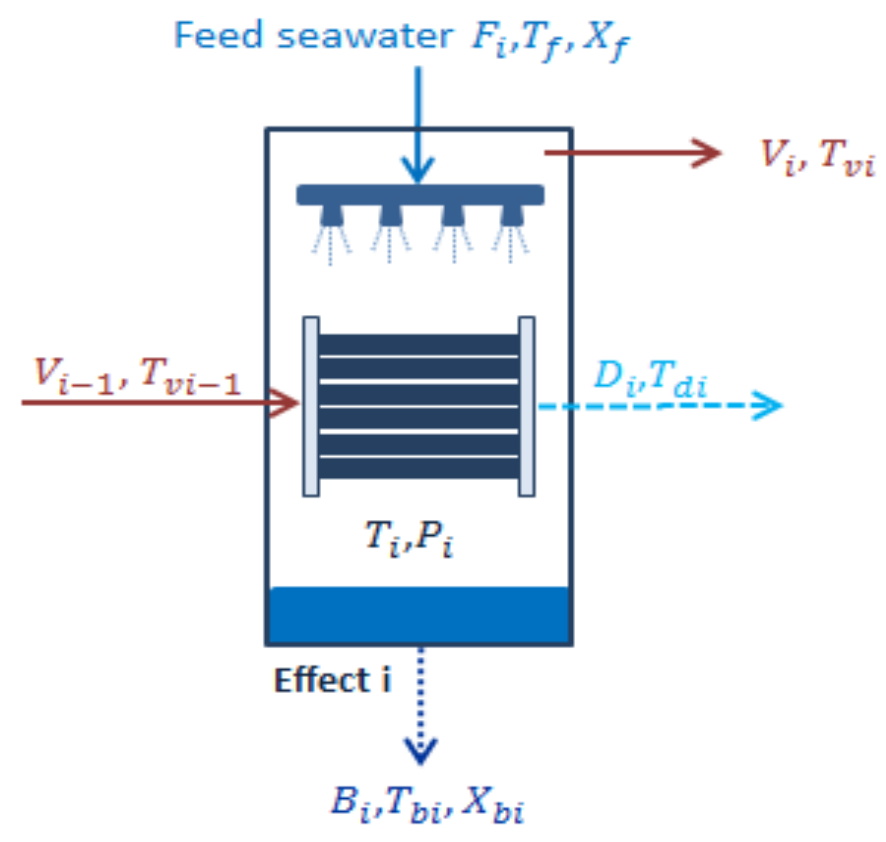

Fig. 2. Scheme and model variables for the i-th effect.

In an effect $\mathrm{i}$, the brine temperature $\mathrm{T}_{\mathrm{bi}}$ is assumed to be equal to the effect temperature $\mathrm{T}_{\mathrm{i}}$ while the vapor temperature $\mathrm{T}_{\mathrm{vi}}$ can be calculated as follows:

$T_{v i}=T_{i}-B P E$

Where the boiling point elevation BPE is the increase in the boiling temperature due to the salts dissolved in the water, calculated with the correlation given in Appendix.

The feed seawater $M_{f}$ is distributed .equally to all effects with mass flow rate $F_{i}$, which can be calculated as follow:

$F_{i}=\frac{M_{f}}{n}$

Where $\mathrm{n}$ is the number of effects in the desalination system. The mass balances in the first and in each effect can be calculated by:

$F_{1}=V_{c v}+B_{1}$

$F_{i}=V_{i}+B_{i}$

Salt balance in the first and each effect can be written as: 


$$
\begin{aligned}
& X_{f 1} F_{1}=X_{b 1} B_{1} \\
& X_{f i} F_{i}=X_{b i} B_{i}
\end{aligned}
$$

Energy balance in the first and each effect is expressed as follows:

$$
\begin{aligned}
& \mathrm{V}_{c v} \lambda_{c v}=F_{1} C_{p 1}\left(T_{1}-T_{f}\right)+V_{1} \lambda_{1} \\
& V_{i-1} \lambda_{i-1}=F_{i} C_{p i}\left(T_{i}-T_{f}\right)+V_{i} \lambda_{i}
\end{aligned}
$$

In which $\mathrm{C}_{\mathrm{pi}}$ is the specific heat capacity for seawater. $\lambda_{i}$ and $\lambda_{c v}$ are the latent heat of vaporization at the effect temperature and at the compressed vapor temperature respectively. These parameters are calculated using the correlations given in the Appendix.

The heat flows in the first and each effect were:

$$
\begin{aligned}
& Q_{e 1}=V_{c v} \lambda_{c v} \\
& Q_{e i}=V_{i} \lambda_{i}
\end{aligned}
$$

Therefore, the heat transfer area of the $\mathrm{i}^{\text {th }}$ effect and the total heat transfer area can be obtained as follows:

$$
\begin{aligned}
& A_{e i}=\frac{Q_{e i}}{U_{e i}(L M T D)_{i}} \\
& A_{t}=\sum_{i=1}^{n} A_{e i}
\end{aligned}
$$

The logarithmic mean temperature difference (LMTD)i. and the overall heat transfer coefficient $\mathrm{U}_{\mathrm{ei}}$ is estimated using the correlations presented by El-Dessouky et al.[2].

$$
\begin{aligned}
& (\text { LMTD })_{i}=\frac{\left(T_{i}-T_{f}\right)}{\ln \left(\frac{T_{v_{i-1}}-T_{f}}{T_{v_{i-1}}-T_{i}}\right)} \\
& U_{e i}=1.9394+1.40562 \times 10^{-3} T_{b i}-2.07525 \times 10^{-5}\left(T_{b i}\right)^{2}+2.3186 \times 10^{-6}\left(T_{b i}\right)^{3}
\end{aligned}
$$

Similarly, the energy balance and the heat transfer area of the condenser can be written as follows:

$$
V_{c} \lambda_{n}=\left(M_{f}+M_{c w}\right) C_{p}\left(T_{f}-T_{s w}\right)
$$

$$
\mathrm{A}_{\mathrm{con}}=\frac{V_{c} \lambda_{n}}{U_{c o n}(L M T D)_{c o n}}
$$


The logarithmic mean temperature difference LMTD and the overall heat transfer coefficient can be calculated using the following equations [2]:

$$
\begin{aligned}
& (\text { LMTD })_{\text {con }}=\frac{\left(T_{v n}-T_{s w}\right)-\left(T_{v n}-T_{f}\right)}{\ln \left(\frac{T_{v n}-T_{s w}}{T_{v n}-T_{f}}\right)} \\
& \mathrm{U}_{\text {con }}=1.7194+3.2063 \times 10^{-2}\left(T_{v n}\right)+1.5971 \times 10^{-5}\left(T_{v n}\right)^{2}+1.9918 \times 10^{-7}\left(T_{v n}\right)^{3}
\end{aligned}
$$

Where $T_{\mathrm{vn}}$ is the vapor temperature of last effect.

The energy balance of the compressor is used to calculate the enthalpy of the compressed vapor $\mathrm{h}_{\mathrm{cv}}$ as follow:

$$
\begin{gathered}
V_{m} h_{m}+V_{e v} h_{e v}=\left(V_{m}+V_{e v}\right) h_{c v} \\
h_{c v}=\left(\frac{\frac{V_{m}}{V_{e v}} h_{m}+h_{e v}}{1+\frac{V_{m}}{V_{e v}}}\right)
\end{gathered}
$$

Where $h_{m}$ and $h_{e v}$ are the specific enthalpy of the motive steam and the entrained vapor, respectively, both estimated with correlations presented in the Appendix.

On other hand, the Entrainment Ratio $(\mathrm{Ra})$ is an essential parameter to evaluate the performance of compressor. It can be determined by several methods available in the literature $[17,25]$. El-Dessouky and Ettouney [2] presented in a semi-empirical model to calculate the entrainment ratio as follows:

$$
R a=0.296 \frac{\left(P_{c v}\right)^{1.19}}{\left(P_{e v}\right)^{1.04}}\left(\frac{P_{m}}{P_{e v}}\right)^{0.015}\left(\frac{P C F}{T C F}\right)
$$

Where $\mathrm{P}_{\mathrm{cv}}, \mathrm{P}_{\mathrm{ev}}$ and $\mathrm{P}_{\mathrm{m}}$ refer to the pressures of compressed vapor, entrained vapor and the motive steam, respectively. PCF and TCF [2] are two correction factors and can be calculated by Eq. (25) and (26). These equations are valid for $10^{\circ} \mathrm{C} \leq T_{e v} \leq 500^{\circ} \mathrm{C}, 100 \mathrm{kPa} \leq P_{m} \leq 3500 \mathrm{kPa}$, $1.81 \leq C R=\frac{P_{c v}}{P_{e v}} \leq 6$ and $R a \leq 4$. 
$P C F=3 \times 10^{-7}\left(P_{m}\right)^{2}-0.0009\left(P_{m}\right)+1.6101$

$T C F=2 \times 10^{-8}\left(T_{e v}\right)^{2}-0.0006\left(T_{e v}\right)+1.0047$

\subsection{Performance parameters}

The following parameters are used to analyze the performance of MED-TVC systems [2]:

- The gain output ratio (GOR) is defined as the ratio .between the distillate produced water and the motive steam.

- The specific cooling water flow rate $\left(\mathrm{sM}_{\mathrm{cw}}\right)$ is defined as. the ratio between the flow rate of produced water and the cooling seawater.

- The specific heat transfer area (sA), which is the ratio between the sum of the heating surface area of equipment (effects and condenser) and the flow rate of product water.

In the thermal desalination units, a specific characteristic related to the first law of thermodynamic, which is defined as the thermal energy consumed by the system to produce 1 $\mathrm{kg}$ of distilled water calculated as [4]:

$s Q=\frac{V_{m} \lambda_{m}}{M_{d}}$

According to the second law of thermodynamic, the specific exergy $\left(S_{e x}\right)$ can be introduced to evaluate the performance of the MED-TVC system. It is defined as the exergy consumed by the motive steam to produce $1 \mathrm{~kg}$ of distillate water when the steam and the liquid assumed to be saturated at ambient temperature $\mathrm{T}_{0}$, is calculated as follows [23]:

$S_{e x}=\frac{V_{m}}{M_{D}}\left[\left(h_{m}-h_{f d}\right)-T_{0}\left(S_{m}-S_{f d}\right)\right]$

Where $S_{m}$ is the specific entropy of inlet motive steam, $h_{f d}$ and $S_{f d}$ are, respectively, the specific enthalpy and entropy of outlet condensate at saturated liquid. These parameters are calculated using correlations in the Appendix.

\section{Economic Model}

The unit product cost for desalination plants depends on many factors as: the capacity, size, type of technology applied and plant location [27-28]. Generally, the units with small size 
( $\leq 5000 \mathrm{~m}^{3} /$ day) exhibit the highest costs, whereas the larger plant capacity reduces the cost for unit product. For the MSF units, which have a daily capacity of 23,000-528,000 $\mathrm{m}^{3}$, the costs of the produced water ranges between 0.52-1.75 $\$ / \mathrm{m}^{3}$. For smaller MED and MED-MVC units (less than $500 \mathrm{~m}^{3} /$ day), their unit product costs is in the range of 2.5 and $10 \$ / \mathrm{m}^{3}$. The costs of existing commercial MED-TVC plants installed in many countries are higher compared with the others capacities for the same desalination technology; in which their unit product cost ranges between 0.5-5.4 \$/ $\mathrm{m}^{3}$ [29-30]. Fig. 3 shows the unit product cost of some existing MED-TVC systems around the world over their total capacity [30].

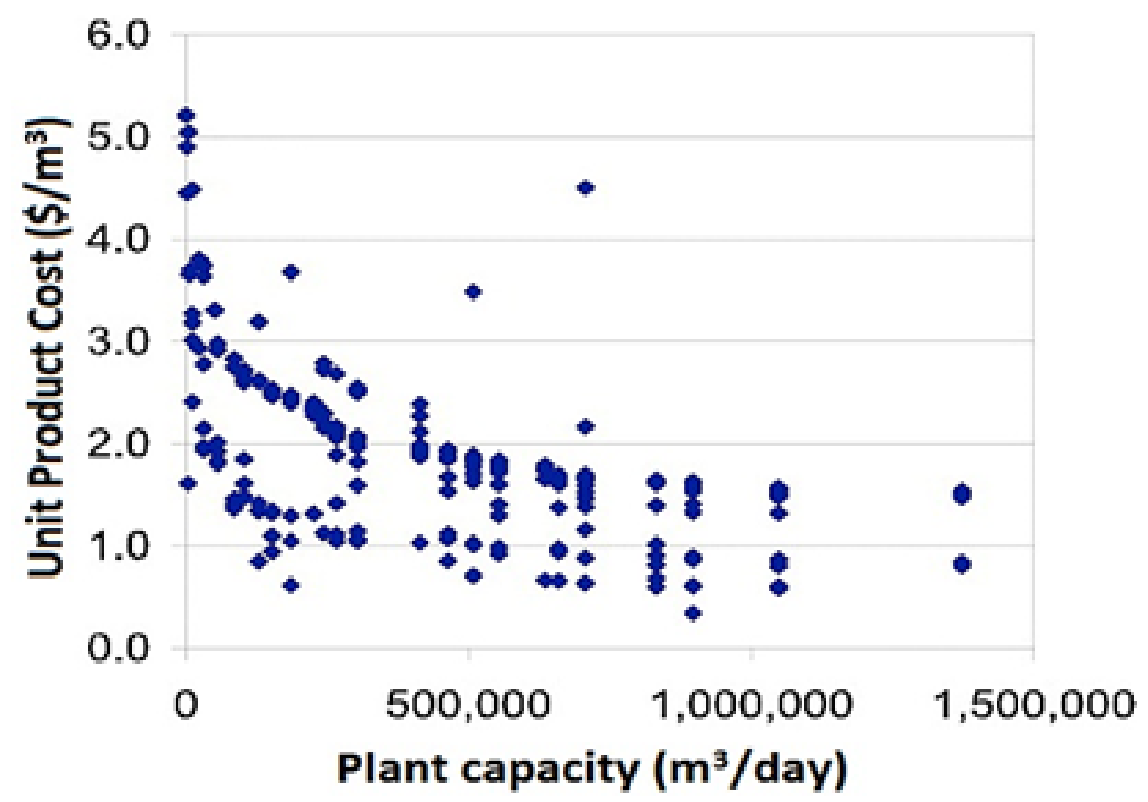

Fig.3. Unit produced costs of commercial MED-TVC systems [30].

In this work, the Total Annualized Cost (TAC) of the SIDEM plant defined as the sum of the capital costs of equipment (CAPEX) and the operational expenses (OPEX) [31].

$T A C=C A P E X+O P E X$

The total capital costs CAPEX accounts the costs of effects evaporator, the condenser and the thermo-compressor. The capital costs of pumps, mixer and splitter are not included in this model. In order to simplify the economic equations, the effects assumed to be one evaporator with total heat transfer are $A_{t}$. The total capital expenditures are given by the following equation [31]: 
$C A P E X=a_{f}\left(\frac{C E P C I_{2015}}{C E P C I_{2001}}\right)\left(\left(C_{p}^{0} F_{B M}\right)_{\text {evaporator }}+\left(C_{p}^{0} F_{B M}\right)_{\text {condenser }}+\left(C_{p}^{0} F_{B M}\right)_{\text {compressor }}\right)$

Where af represent the amortization factor which is given by the following equation:

$$
a_{f}=\frac{i_{r}\left(i_{r}+1\right)^{y}}{\left(i_{r}+1\right)^{y}-1}
$$

Where $i_{r}$ refers to the interest rate per year and $y$ is the number of years.

In Eq. (30), $C_{p}^{0}$ indicates the basic cost of a unitary equipment (in US\$) operating at pressure close to ambient conditions. F BM $_{\mathrm{BM}}$ corresponds to the correction factor for the unitary equipment cost, in which the materials of construction and the operational pressure of the equipment are correlated [28, 32].

The basic unitary cost of the condenser is estimated using the correlations proposed by Turton et al. [28] which depends on the heat transfer area and the pressure of condenser. To estimate the unitary cost of the evaporator and compressor, the Couper et al.'s correlations [32] are used in the model. These correlations depend on the heat transfer area for the evaporator and for the thermal vapor compressor depend on the mass flow rate and the pressure of the entrained vapor. In addition, in Eq. (30), the costs should be corrected with the Chemical Engineering Plant Cost Index (CEPCI).

Operational expenditures account the steam consumed by the thermo-vapor compressor and expressed as:

$$
O P E X=C_{\text {steam }} Q_{s}
$$

where $\mathrm{C}_{\text {steam }}$ is the specific steam cost giving by the GCT factory data. The term $\mathrm{Q}_{\mathrm{s}}$ indicates the annual steam consumption.

Finally, the cost of produced water per $\mathrm{m}^{3}$ can be written as:

$$
C_{\text {porduction }}\left(\$ / \mathrm{m}^{3}\right)=\frac{T A C(\$ / \text { year })}{3600 \times 24 \times 350 \times Q_{p}\left(\mathrm{~m}^{3} / \mathrm{s}\right)}
$$

Where $\mathrm{Q}_{\mathrm{p}}$ is the volumetric flow rate of produced water.

\section{Problem formulation}


The objective function is to minimize the total annualized cost (TAC) of the desalination process. The purpose of this paper is to use a combination between Matlab as a process optimizer and Aspen HYSYS as a process simulator to solve the problem.

Matlab R2013a is used to implement the equations model. The function 'fmincon' used to find the minimum TAC [33-34] from several equations based on vector of variables between minimum and maximum values and under defined constraints. The Sequential Quadratic Programming (SQP) algorithm has been chosen as a method to solve the non-linear problem based on successive iterations to find the feasible solutions [34-35].

The desalination unit is modeled using Aspen HYSYS 8.4 for a steady state simulation. Due to the specific characteristics of seawater, NRTL-electrolyte fluid package was chosen in this study to calculate equilibrium and thermodynamics properties [13]. The flowsheet in Aspen HYSYS is shown in Fig.5.

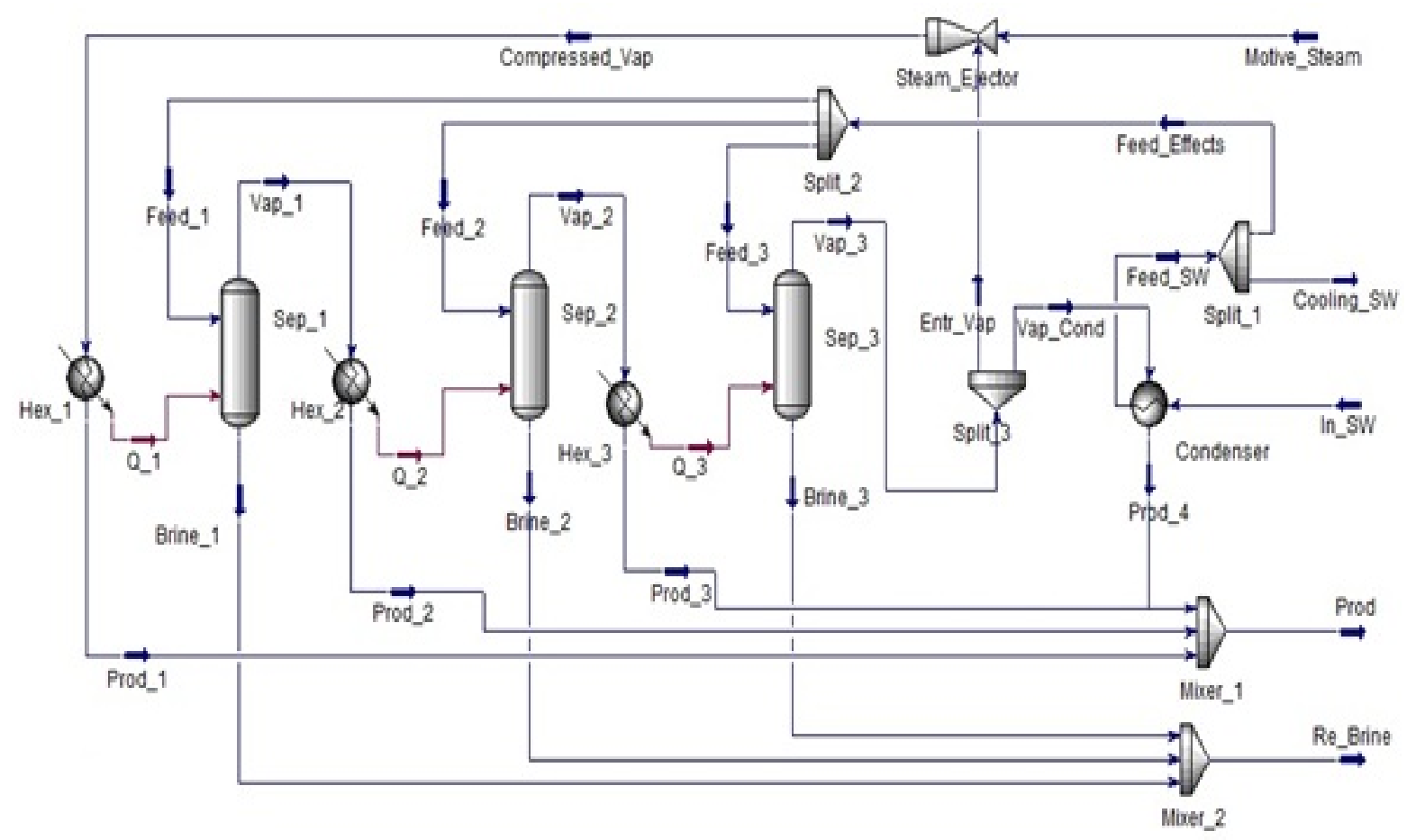

Fig. 5. Aspen HYSYS flowsheet for SIDEM unit.

The connection between Matlab and Aspen HYSYS is done via the Component Objective Model (COM) interface of Microsoft with ActiveX technology [34]. The initial values are provided in Matlab in which transfers the parameters to Aspen HYSYS. Then, Aspen HYSYS is employed to simulate the desalination system through the flowsheet. Aspen HYSYS returns 
the simulations results to Matlab; the TAC is calculated and the constraints function is verified. This iterative process is carried out until the convergence criteria are satisfied and the final results are obtained [36-38]. The flow diagram of the connection between Aspen HYSYS and Matlab is shown in Fig.6.

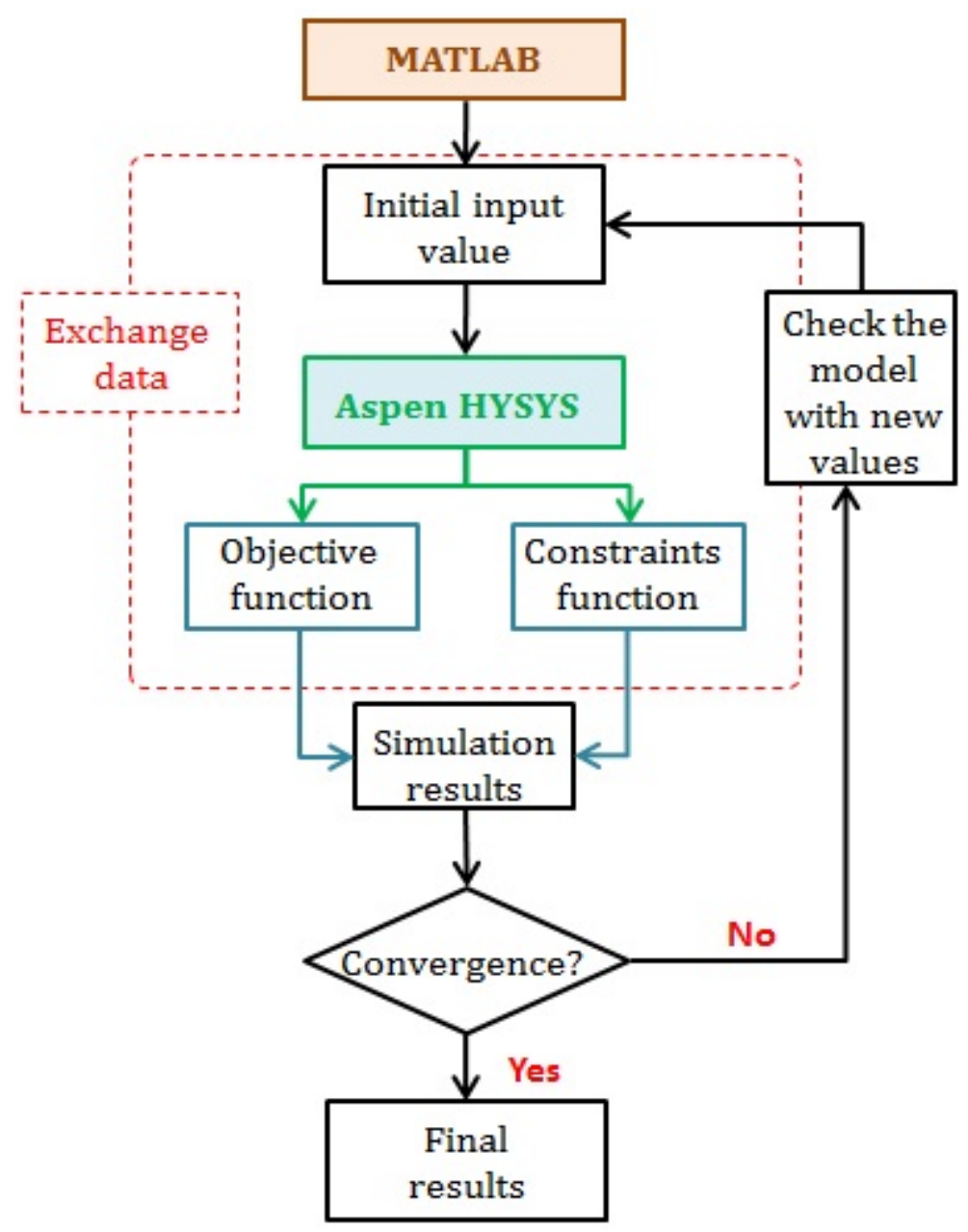

Fig.6. Flowchart of the proposed combination.

The selected decisions variables in this work are: mass flow rate and pressure of the motive steam, temperature of feed sea water to effects, pressure of the last effect and the pressure of the compressed vapor pressure (output of TVC). Furthermore, the linear and nonlinear constraints of the problem are introduced below. 
To avoid temperature crosses among effects, the following conditions must be satisfied:

$T_{i}>T_{i+1}$

$\Delta T=10^{\circ} \mathrm{C}$

During the simulation no pressure drop in the intercooler and the effect pressure should be decrease from an effect to other in which streams pressures are limited by:

$P_{i}>P_{i+1}$

For environmental limited the salt .concentration of the rejected brine is limited with upper value as follow:

$X_{B} \leq 70,000 \mathrm{ppm}$

\section{Case study and Results}

\subsection{Case study}

The parameters used in this study of the SIDEM unit presented by the Phosphoric Acid Plant owned by the GCT factory installed in Gabes (south of Tunisia) and shown in Table1. Table 2 summarizes the required parameters for the economic model.

Table 1- The operating parameters.

\begin{tabular}{c|lc}
\hline Parameter (unit) & & Value \\
\hline \multirow{4}{*}{ Seawater } & Mass flow rate (t/h) & 220 \\
\cline { 2 - 3 } & Temperature $\left({ }^{\circ} \mathrm{C}\right)$ & 28 \\
\cline { 2 - 3 } & Pressure (bar) & 3 \\
\cline { 2 - 3 } & Salinity (ppm) & 39,000 \\
\hline \multirow{4}{*}{ Motive Steam } & Mass flow rate (t/h) & 3 \\
\cline { 2 - 3 } & Temperature $\left({ }^{\circ} \mathrm{C}\right)$ & 170 \\
\cline { 2 - 3 } Condenser & Pressure (bar) & 5 \\
\hline \multirow{4}{*}{ Ejector } & Pressure drop tube (bar) & 0.3 \\
\cline { 2 - 3 } & Pressure drop shell (bar) & 0 \\
\cline { 2 - 3 } & Temperature drop $\left({ }^{\circ} \mathrm{C}\right)$ & 4 \\
\hline \multirow{4}{*}{ Effects } & Pressure output $(\mathrm{bar})$ & 0.25 \\
\cline { 2 - 3 } & Temperature $1\left({ }^{\circ} \mathrm{C}\right)$ & 60 \\
\cline { 2 - 3 } & Temperature $2\left({ }^{\circ} \mathrm{C}\right)$ & 50 \\
\cline { 2 - 3 } & Temperature 3 $\left({ }^{\circ} \mathrm{C}\right)$ & 40 \\
\hline
\end{tabular}




\begin{tabular}{c|lc}
\hline Cooling seawater & Mass flow rate $(\mathrm{t} / \mathrm{h})$ & 160 \\
\hline Feed to effects & Mass flow rate $(\mathrm{t} / \mathrm{h})$ & 20 \\
\hline
\end{tabular}

Table 2- Economic parameters.

\begin{tabular}{lc}
\hline Parameters & Value \\
\hline Cost of Steam $\mathrm{C}_{\text {steam, }} \$$ /ton & 16.61 \\
\hline Amortization year $y$, year & 10 \\
\hline Interest rate $i_{r}, \%$ & 10 \\
\hline Annual Operating Hours & $24 \times 350$ \\
\hline
\end{tabular}

\subsection{Simulation Results}

The proposed model presented in the paper is validated with results from the GCT factory. The comparison between the calculated results by the model and the industrial data, as mentioned in Table3, shows an accuracy of $\pm 10 \%$. The total distillate capacity of the system is $22.87 \mathrm{t} / \mathrm{h}$ while the feed seawater flow rate to effects is $60 \mathrm{t} / \mathrm{h}$. In addition, $1.5 \mathrm{ton} / \mathrm{h}$ of vapor condensate in the condenser and causes the increase of the input seawater temperature around $4^{\circ} \mathrm{C}$. On other hand, the salinity of rejected brine is $58,300 \mathrm{ppm}$ with temperature about $40^{\circ} \mathrm{C}$, which is lower than the limited value indicated the constraints. This value cannot be supplied by the factory. Fig. 7 shows the different values of produced water flow rate in the SIDEM unit. It can be seen that the first effect produces the high value of fresh water with 7.09 ton/h.

Table 3- Comparison of simulation results and industrial plant data.

\begin{tabular}{lccc}
\hline Parameters (unit) & Calculated & Actual & Deviation (\%) \\
\hline Total distillated produced water $\mathrm{M}_{\mathrm{D}}(\mathrm{t} / \mathrm{h})$ & 22.8704 & 21.67 & $+5.54 \%$ \\
Temperature of produced water $\mathrm{T}_{\mathrm{D}}\left({ }^{\circ} \mathrm{C}\right)$ & 39.65 & $\mathrm{NA}^{\mathrm{a}}$ & - \\
Seawater Temperature $\mathrm{T}_{\mathrm{sw}}\left({ }^{\circ} \mathrm{C}\right)$ & 28 & 28 & - \\
Number of effects & 3 & 3 & -
\end{tabular}




\begin{tabular}{lccc} 
Feed seawater temperature $\mathrm{T}_{\mathrm{f}}\left({ }^{\circ} \mathrm{C}\right)$ & 32 & 32 & - \\
Total rejected brine flow rate $\mathrm{M}_{\mathrm{B}}(\mathrm{t} / \mathrm{h})$ & 40.1256 & 41.33 & $-2.9 \%$ \\
Salinity of rejected brine $\mathrm{X}_{\mathrm{B}}(\mathrm{ppm})$ & 58,300 & $\mathrm{NA}^{\mathrm{a}}$ & - \\
Temperature of rejected brine $\mathrm{T}_{\mathrm{B}}\left({ }^{\circ} \mathrm{C}\right)$ & 40.01 & $\mathrm{NA}^{\mathrm{a}}$ & - \\
Vapor enter to condenser $\mathrm{V}_{\mathrm{c}}(\mathrm{t} / \mathrm{h})$ & 1.5048 & $\mathrm{NA}^{\mathrm{a}}$ & - \\
Pressure of last effect $\mathrm{P}_{3}(\mathrm{bar})$ & 0.07248 & 0.074 & $-2.054 \%$ \\
Cooling seawater $\mathrm{M}_{\mathrm{cw}}(\mathrm{t} / \mathrm{h})$ & 160 & 160 & - \\
\hline
\end{tabular}

a: Not Available

The feed seawater is distributed equally between all effects with mass flow rate $20 \mathrm{t} / \mathrm{h}$ and temperature $32^{\circ} \mathrm{C}$. The simulated results for the three effects of SIDEM unit are presented in Table 4. The decrease of effect temperature leads to reduction in the energy consumption and the overall heat transfer coefficients. The heat input to each effect is required to produce from the feed seawater. It should be highlighted that in all effects, approximately, 30\% of mass flow rate of seawater evaporate and the average $\mathrm{BPE}$ losses alone are $0.8^{\circ} \mathrm{C}$.

Table 4-Results of simulation.

\begin{tabular}{lccc}
\hline Parameter (unit) & Effect1 & Effect2 & Effect3 \\
\hline Temperature $\mathrm{T}_{\mathrm{i}}\left({ }^{\circ} \mathrm{C}\right)$ & 60 & 50 & 40 \\
Produced water mass flow rate $\mathrm{D}_{\mathrm{i}}(\mathrm{t} / \mathrm{h})$ & 7.9452 & 7.056 & 6.3684 \\
Produced vapor mass flow rate $\mathrm{V}_{\mathrm{i}}(\mathrm{t} / \mathrm{h})$ & 7.056 & 6.3684 & 6.4512 \\
Temperature of Produced vapor $\left.\mathrm{T}_{\mathrm{vi}}{ }^{\circ} \mathrm{C}\right)$ & 59.2241 & 49.2561 & 39.2870 \\
Outline brine flow rate $\mathrm{B}_{\mathrm{i}}(\mathrm{ton} / \mathrm{h})$ & 12.9456 & 13.6332 & 13.5504 \\
Overall heat transfer coefficients $\mathrm{U}_{\mathrm{ei}}\left(\mathrm{kW} / \mathrm{m}^{20} \mathrm{C}\right)$ & 2.4498 & 2.2476 & 2.1108 \\
Heat flow $\mathrm{Q}_{\mathrm{ei}}(\mathrm{kW})$ & 5267 & 4631 & 4501 \\
Heat transfer area $\left(\mathrm{m}^{2}\right)$ & 97.4735 & 246.5064 & 234.4532 \\
\hline
\end{tabular}

Fig. 7 shows a comparison between the simulations results and the industrial values of the pressure inside the three effects of SIEDM unit. Good agreement was found between the simulations results and the actual data from the factory. The pressure effects decrease from 0.1955 bar in the first effect to 0.07248 bar in the last effect. 


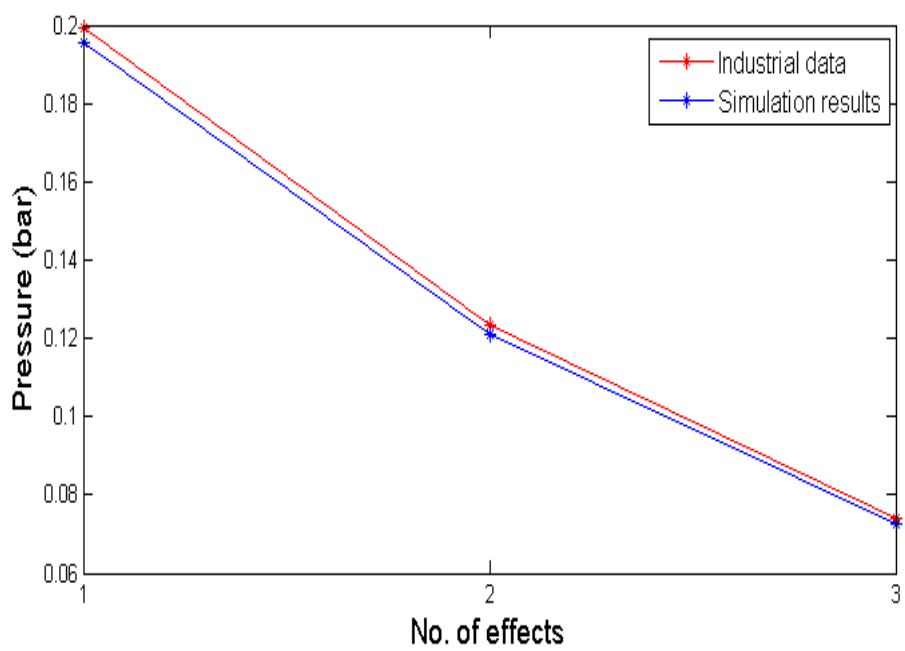

Fig. 7. Comparison of simulation results and actual data of pressure effects.

The simulation results of the thermo-vapor compressor and the industrial data are listed in Table 5. The motive steam entrained $4.946 \mathrm{t} / \mathrm{h}$ of vapor from the last effect with a pressure of 0.07248 bar. The compressor of the SIDEM unit has a higher CR value (around 3.42) compared to other units in literature [2-4]. As shown by Table 5, the pressures values deviations between the actual data and the simulations results induce the change of the CR value.

Table 5-Results of simulation of the thermal vapor compressor.

\begin{tabular}{lllc}
\hline Parameters (unit) & Calculated & Actual & Deviation (\%) \\
\hline Entrained vapor flow rate $\mathrm{V}_{\mathrm{ev}}(\mathrm{t} / \mathrm{h})$ & 4.9464 & 4.55 & $+8.712 \%$ \\
Temperature of compressed vapor $\mathrm{T}_{\mathrm{cv}}\left({ }^{\circ} \mathrm{C}\right)$ & 84.5 & 90 & $-6.11 \%$ \\
Pressure of entrained vapor $\mathrm{P}_{\mathrm{ev}}(\mathrm{bar})$ & 0.07248 & 0.074 & $-2.054 \%$ \\
Pressure of compressed vapor $\mathrm{P}_{\mathrm{cv}}(\mathrm{bar})$ & 0.248 & 0.25 & $-0.8 \%$ \\
Compression Ratio CR & 3.42 & 3.39 & $-0.8 \%$ \\
The Entrainment Ratio Ra & 2.31 & - & - \\
Specific enthalpy of compressed vapor $\mathrm{H}_{\mathrm{cv}}(\mathrm{kJ} / \mathrm{kg})$ & 2650.6 & $\mathrm{NA}^{\mathrm{a}}$ & - \\
\hline
\end{tabular}

The performance parameters of the SIDEM plant are illustrated in Table 6. The specific heat transfer area As obtained by this simulation is 96.79, which is very low compared to the literature [4-11]. This parameter is defined as the ratio between the sum of heat transfer area of all effects and the condenser to the produced water mass flow rate. On the other hand, the overall heat transfer coefficients in all effect is in the average of $2.4 \mathrm{~kW} /\left(\mathrm{m}^{2 \circ} \mathrm{C}\right)$. Any change in the temperatures leads to change in the heat transfer areas. As it can be seen, both of the specific 
heat and exergy consumptions have higher values. It is because they are related to the mass flow rate and the temperature of the motive steam, which is supplied directly from the boiler and consequently higher motive steam pressure (and temperature) needed a higher energy. It can be reported from this table that the GOR value is 7.6235 while the actual value is 7.223. As the input motive steam flow rate to the unit is constant, the GOR value is directly related to the produced fresh water flow rate. The calculation results show that the production cost is 4.1712 $\$ / \mathrm{m}^{3}$ and less than the cost presents by the GCT factory which is $4.8 \$ / \mathrm{m}^{3}$. This difference could be explained by the economic assumptions used in this model.

Table 6- System performance.

\begin{tabular}{lc}
\hline Parameter (unit) & Model \\
\hline Specific cooling water flow rate $\mathrm{sM}_{\mathrm{cw}}$ & 0.1429 \\
Specific heat transfer area sA $\left(\mathrm{m}^{2} / \mathrm{kg} / \mathrm{s}\right)$ & 96.7909 \\
Specific heat consumption sQ $(\mathrm{kJ} / \mathrm{Kg})$ & 268.8019 \\
Specific exergy consumption $\mathrm{S}_{\mathrm{ex}}(\mathrm{kJ} / \mathrm{Kg})$ & 320.7198 \\
Gain output ratio GOR & 7.6235 \\
Unit water cost $\left(\$ / \mathrm{m}^{3}\right)$ & 4.1712 \\
\hline
\end{tabular}

\subsection{Parametric study}

A parametric study was carried out and it is reported below for the SIDEM desalination unit to study the sensitivity analysis of the variation of; the motive steam mass flow rate, motive steam pressure and the feed seawater temperature to effects on the system's performance and the unit product cost.

\subsubsection{Effect of motive steam flow rate:}

The influence of the motive steam flow variation from 2 to $4 \mathrm{t} / \mathrm{h}$ on the total produced flow rate and the GOR values are shown in Fig. 8. The increase of the motive steam flow leads to 31\% of produced flow rate increase and 34\% of the GOR decrease. Fig. 9 shows that the variation of the motive steam flow has a higher influence on the specific heat consumption and specific exergy consumption. That causes increase of $50 \%$ of specific heat consumption and $47 \%$ of the specific exergy consumption. The addition of steam flow rate leads to an increase in the temperature and the pressure of compressed vapor, which need a higher energy to evaporate the seawater in all effects. Furthermore, the motive steam flow variation shows a reduction in 
specific heat transfer area of $12.42 \%$ and an increasing of $11 \%$ in the salinity of rejected brine (from 55,400 to 61,500 ppm). Furthermore, in this case, the addition of the motive steam flow to the unit can decrement the produced water cost to $20.6 \%$ as indicated in Fig. 10.

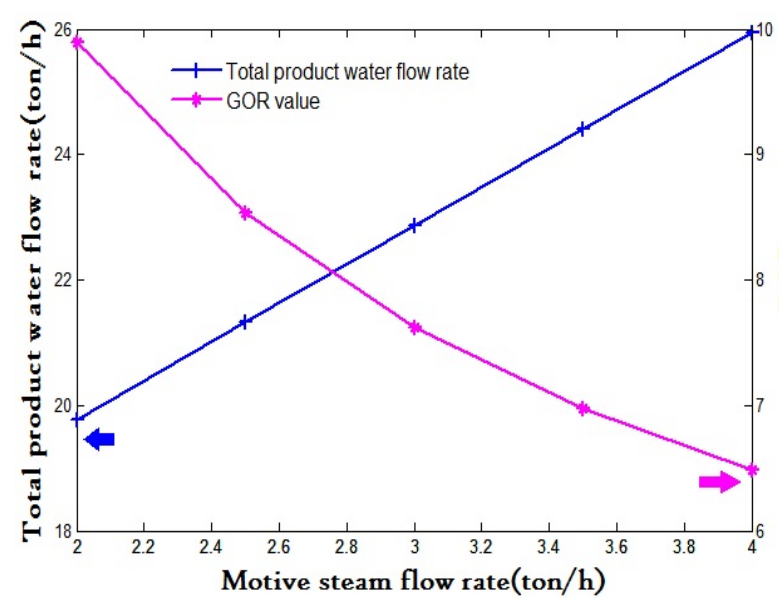

Fig. 8. Effect of motive steam flow rate on the total produced water flow rate and GOR.

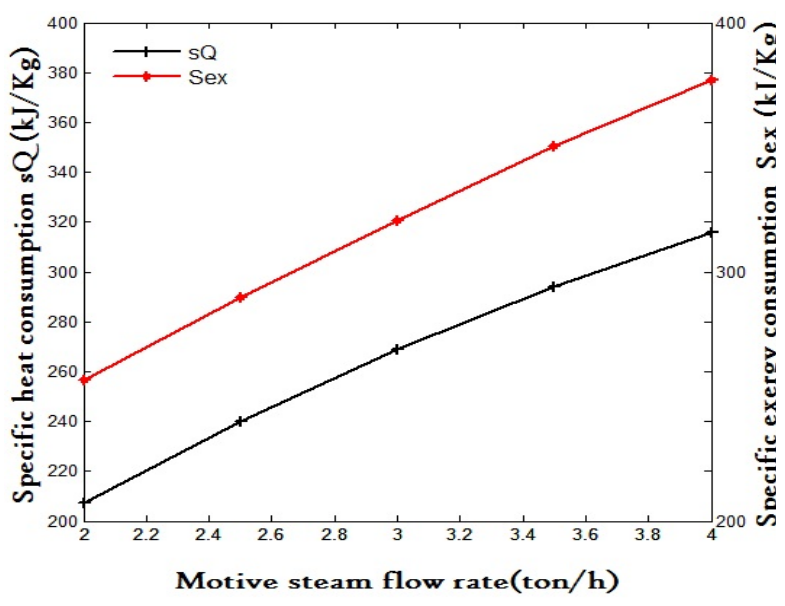

Fig. 9. Effect of motive steam flow rate on the specific heat consumption and specific exergy consumption.

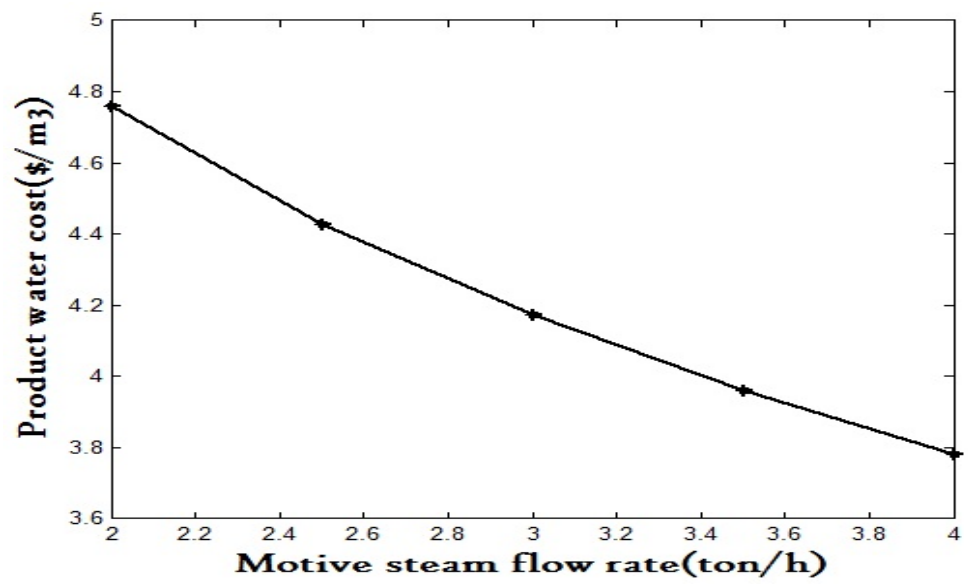

Fig. 10. Effect of motive steam flow rate on the unit produced water cost.

\subsubsection{Effect of motive steam pressure:}

The effect of the motive steam pressure variation on the total produced water and the GOR of the unit are presented in Fig.11. An increase of the motive steam pressure from 1 to 7 bar leads to a reduction lower than $1 \%$ of both total produced water and the GOR values. Moreover, the increase of the motive steam pressure giving a slight variation on the specific heat and exergy consumptions as shown in Fig. 12. Fig. 13 shows that the increase of $\mathrm{P}_{\mathrm{m}}$ leads to $5 \%$ increase of As. As a results of $\mathrm{P}_{\mathrm{m}}$ variation, the pressure of compressed vapor increases from 0.23 to 
0.25 bars, the temperature of the compressed vapor is $8^{\circ} \mathrm{C}$ lower and the produced water cost increases is around $1.9 \%$ (4.12 to $\left.4.2 \$ / \mathrm{m}^{3}\right)$.

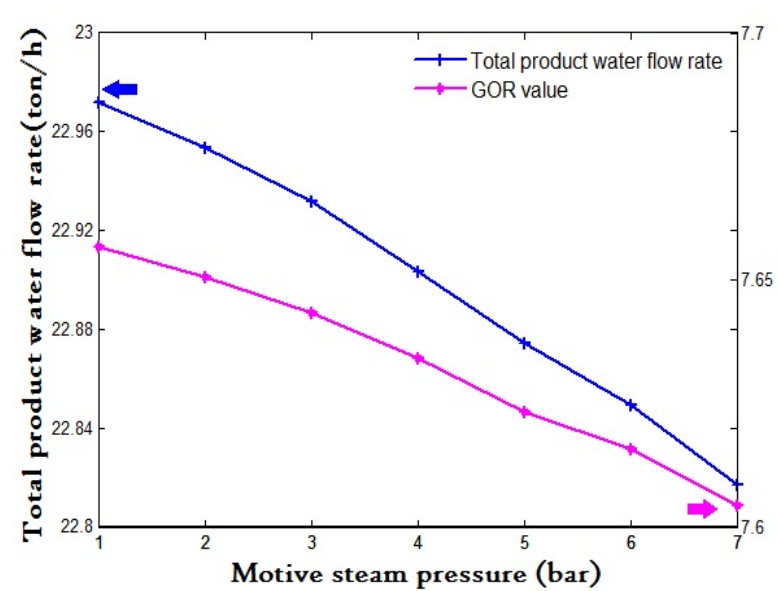

Fig. 11. Effect of motive steam pressure on the total produced water flow rate and GOR.

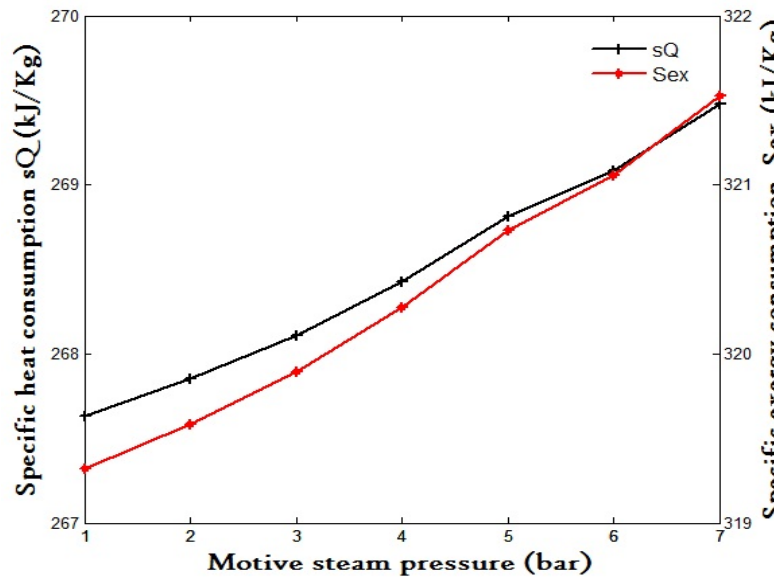

Fig. 12. Effect of motive steam pressure on the specific heat consumption and specific exergy consumption.

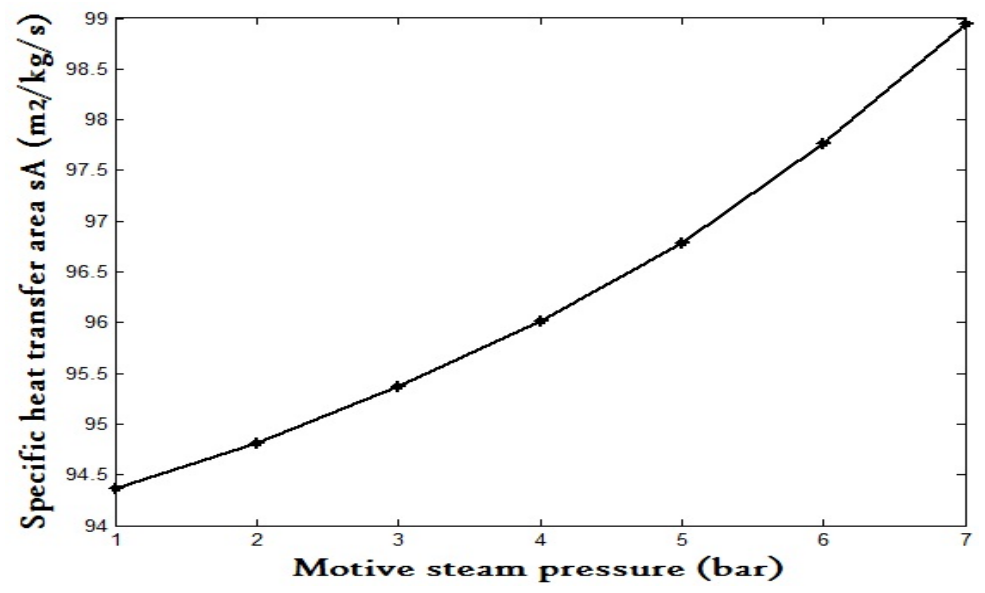

Fig. 13. Effect of motive steam pressure on the specific heat transfer area.

\subsubsection{Effect of feed sea water temperature}

The effect of the feed seawater to effects temperature variation on the produced water mass flow rate and the GOR value is shown in Fig. 14. The increase of the temperature from 29 to $36{ }^{\circ} \mathrm{C}$ causes about $18 \%$ decrease in the produced water mass flow and the GOR. In addition, the temperature of compressed vapor (outlet the TVC) increases by $15^{\circ} \mathrm{C}$ which decreases the specific heat transfer area of the effects. As the mass flow rate of the feed seawater is constant, the temperature variation reduces the salinity of rejected brine from 61,300 to $54,800 \mathrm{ppm}$. As shown in Fig. 15, the two specific heat and exergy consumptions increase by $22 \%$ and $26 \%$, 
respectively. The effect of increasing the feed temperature on the produced water cost of the unit is shown in Fig. 16. It causes the rise in the cost value with $7 \%\left(4.07\right.$ to $\left.4.36 \$ / \mathrm{m}^{3}\right)$.

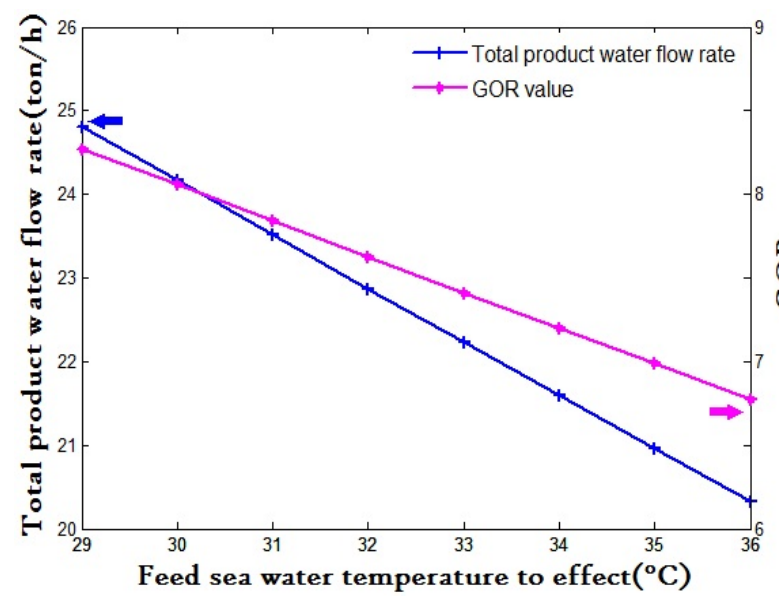

Fig. 14. Effect of feed seawater temperature on the total produced water flow rate and GOR.

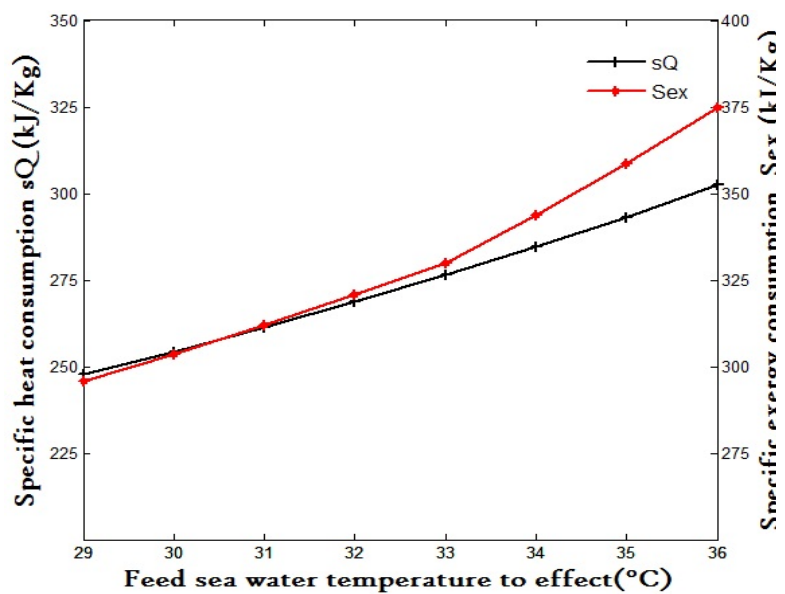

Fig. 15. Effect of feed seawater temperature on the specific heat consumption and specific exergy consumption.

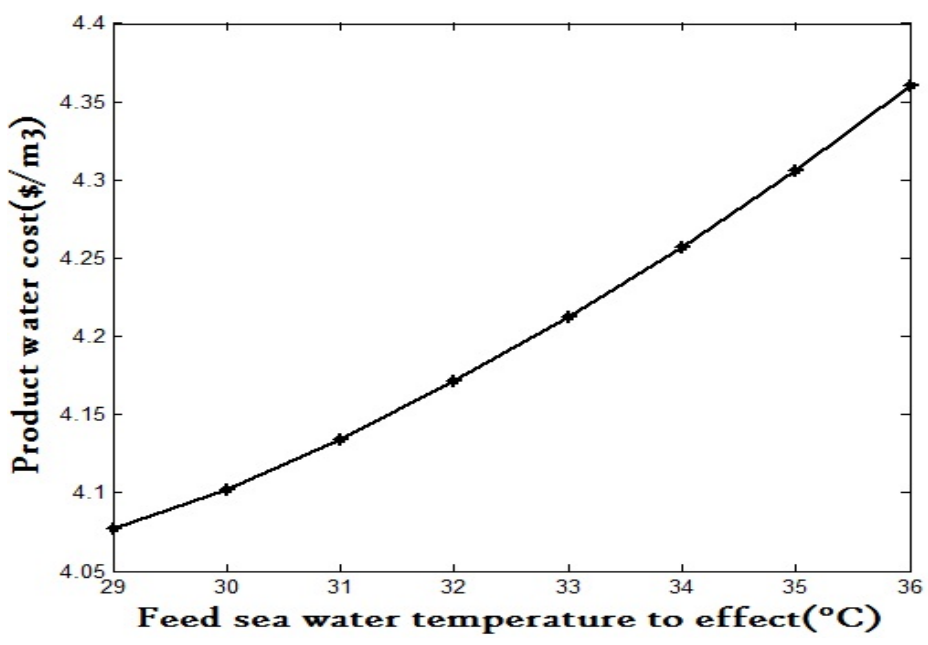

Fig. 16. Effect of feed sea water temperature on the unit product water cost.

\section{Conclusions}

This paper presents a modeling and simulation of a MED-TVC desalination system located in the GCT factory in Tunisia. A mathematical and economic model was developed and used to minimize the total annual cost of the unit. This paper proposed a new connection between a process optimizer and process simulator is investigated to solve the problem. The configuration 
of problem was built with five decision variables and feasibility constraints as the salinity of rejected brine. Simulation results show a good agreement with the actual data from the factory. Moreover, parametric analyses of the SIDEM unit performance were established. The increase in motive steam flow rate causes about $20.6 \%$ reduction in the product cost. In addition, the increase of feed seawater temperature to effects causes about $7 \%$ rise in the cost. The increase in the pressures of motive steam and compressed vapor increase about $1 \%$ in the product cost.

\section{Acknowledgements}

This work was supported by the Applied Thermodynamics Research Unit (UR 11ES80) and the University of Gabes (Tunisia).The authors would like to think the Ministry of Higher Education and Scientific Research of Tunisia for the financial scholarship. Authors would like to express their appreciation to the Institute of Chemical Process Engineering in the University of Alicante (Spain) for their valuable collaboration.

\section{Nomenclature}

$\begin{array}{ll}A & \text { Heat transfer area, } \mathrm{m}^{2} \\ B & \text { Brine flow rate, ton } / \mathrm{h} \\ B P E & \text { Boiling point elevation, }{ }^{\circ} \mathrm{C} \\ C_{p} & \text { Specific heat capacity of water, } \mathrm{kJ} / \mathrm{kg}^{\circ} \mathrm{C} \\ C R & \text { Compression ratio } \\ D & \text { Mass flow rate of distillate, ton } / \mathrm{h} \\ F_{B M} & \text { Correction factor for the capital cost } \\ F & \text { Feed seawater flow rate, ton } / \mathrm{h} \\ H & \text { Specific enthalpy, } \mathrm{kJ} / \mathrm{kg} \\ i_{r} & \text { Factor of annualized capital cost } \\ L M T D & \text { Logarithmic mean temperature difference },{ }^{\circ} \mathrm{C} \\ M & \text { Mass flow rate, ton } / \mathrm{h} \\ M_{B} & \text { Rejected Brine, ton } / \mathrm{h} \\ n & \text { Number of effects, Last effect } \\ N E A & \text { Non-equilibrium allowance, }{ }^{\circ} \mathrm{C} \\ P & \text { Pressure, kPa } \\ p p m & \text { Parts per million } \\ Q_{e} & \text { Heat flow in effect, } \mathrm{kW}\end{array}$




$\begin{array}{ll}R_{a} & \text { The Entrainment Ratio } \\ S & \text { Specific entropy, } \mathrm{kJ} / \mathrm{kg}^{\circ} \mathrm{C} \\ s & \text { Salinity, g/kg } \\ s A & \text { Specific heat transfer area, } \mathrm{m}^{2} / \mathrm{kg} / \mathrm{s} \\ T & \text { Temperature, }{ }^{\circ} \mathrm{C} \\ U & \text { Overall heat transfer coefficient, } \mathrm{kW} / \mathrm{m}^{2 \circ} \mathrm{C} \\ V & \text { Vapor mass flow rate, ton } / \mathrm{h} \\ X & \text { Salt concentration, ppm } \\ \Delta T & \text { Temperature difference between effects, }{ }^{\circ} \mathrm{C}\end{array}$

\section{Greek symbols}
$\lambda$
Latent heat of evaporation, $\mathrm{kJ} / \mathrm{kg}$

\section{Subscripts}

$\begin{array}{ll}b & \text { Brine } \\ c & \text { Vapor to condenser } \\ c o n & \text { Condenser } \\ c v & \text { Compressed vapor } \\ c w & \text { Cooling seawater } \\ d & \text { Distillate product } \\ e & \text { effect } \\ e q & \text { Inequality } \\ e v & \text { Entrained vapor } \\ e v p & \text { Evaporator } \\ f & \text { Feed seawater to effects } \\ i: 1,2,3 & \text { Effect index } \\ m & \text { Motive steam } \\ s w & \text { Input seawater } \\ t & \text { total } \\ v & \text { Vapor formed from boiling } \\ y & \text { year }\end{array}$




\section{Appendix: Thermodynamics properties of Seawater [2, 39-40]}

The thermodynamics properties of seawater are equations depends on temperature $T$ and salinity $X$, they are as below:

- The seawater specific heat capacity $\mathrm{C}_{\mathrm{p}}$ :

$$
\mathrm{C}_{\mathrm{p}}=\left[\mathrm{A}+\mathrm{BT}+\mathrm{CT}^{2}+\mathrm{DT}^{3}\right] \times 10^{-3}
$$

The variables A, B, C and D are a function of the water salinity as follows:

$$
\begin{aligned}
& A=4206.8-6.6197 \mathrm{~s}+1.2288 \times 10^{-2} \mathrm{~s}^{2} \\
& B=-1.1262+5.4178 \times 10^{-2} \mathrm{~s}-2.2719 \times 10^{-4} \mathrm{~s}^{2} \\
& C=1.2026 \times 10^{-2}-5.3566 \times 10^{-4} \mathrm{~s}+1.8906 \times 10^{-6} \mathrm{~s}^{2} \\
& D=6.8777 \times 10^{-7}+1.517 \times 10^{-6} \mathrm{~s}-4.4268 \times 10^{-9} \mathrm{~s}^{2}
\end{aligned}
$$

where $\mathrm{C}_{\mathrm{p}}$ in $\mathrm{kJ} /\left(\mathrm{kg}^{\circ} \mathrm{C}\right)$, $\mathrm{T}$ in ${ }^{\circ} \mathrm{C}$ and $\mathrm{s}$ in $\mathrm{g} / \mathrm{kg}$. This correlation is valid over the salinity and temperature ranges of $20,000 \leq X \leq 160,000 \mathrm{ppm}$ and $20 \leq T \leq 180^{\circ} \mathrm{C}$, respectively.

- The Boiling Point Elevation BPE:

$$
\mathrm{BPE}=\mathrm{X}(\mathrm{B}+\mathrm{CX}) 10^{-3}
$$

with the variables $\mathrm{B}$ and $\mathrm{C}$ are a function of temperature as follows:

$$
\begin{aligned}
& B=\left(6.71+6.34 \times 10^{-2} \mathrm{~T}+9.74 \times 10^{-5} \mathrm{~T}^{2}\right) 10^{-3} \\
& \mathrm{C}=\left(22.238+9.59 \times 10^{-3} \mathrm{~T}+9.42 \times 10^{-5} \mathrm{~T}^{2}\right) 10^{-8}
\end{aligned}
$$

where BPE and $\mathrm{T}$ in ${ }^{\circ} \mathrm{C}$ and $\mathrm{X}$ in $\mathrm{ppm}$.

- The Latent heat of vaporization $\lambda$

$$
\lambda=2501.897149-2.407064037 \mathrm{~T}+1.192217 \times 10^{-3} \mathrm{~T}^{2}-1.5863 \times 10^{-5} \mathrm{~T}^{3}
$$

where $\lambda$ in $\mathrm{kJ} / \mathrm{kg}$ and $\mathrm{T}$ in ${ }^{\circ} \mathrm{C}$.

- The specific enthalpy of saturated liquid water $\mathrm{h}_{1}$ : 
$h_{1}=-0.033635409+4.20755011 T-6.200339 \times 10^{-4} T^{2}+4.459374 \times 10^{-6} \mathrm{~T}^{3}$

where $\mathrm{h}_{\mathrm{l}}$ in $\mathrm{kJ} / \mathrm{kg}$ and $\mathrm{T}$ in ${ }^{\circ} \mathrm{C}$.

- $\quad$ The specific enthalpy of saturated vapor water $h_{\mathrm{v}}$ :

$h_{v}=2501.689845+1.806916015 \mathrm{~T}+5.087717 \times 10^{-4} \mathrm{~T}^{2}-1.1221 \times 10^{-5} \mathrm{~T}^{3}$

where $\mathrm{h}_{\mathrm{v}}$ in $\mathrm{kJ} / \mathrm{kg}$ and $\mathrm{T}$ in ${ }^{\circ} \mathrm{C}$.

- The specific entropy of saturated liquid water $\mathrm{S}_{1}$ :

$S_{1}=-0.00057846+0.015297489 \mathrm{~T}-2.63129 \times 10^{-5} \mathrm{~T}^{2}+4.11959 \times 10^{-8} \mathrm{~T}^{3}$

where $\mathrm{S}_{1}$ in $\mathrm{kJ} /\left(\mathrm{kg}^{\circ} \mathrm{C}\right)$ and $\mathrm{T}$ in ${ }^{\circ} \mathrm{C}$.

- $\quad$ The specific entropy of saturated vapor water $S_{\mathrm{v}}$ :

$\mathrm{S}_{\mathrm{v}}=9.149505306-2.581012 \times 10^{-2} \mathrm{~T}+9.625687 \times 10^{-5} \mathrm{~T}^{2}-1.786615 \times 10^{-7} \mathrm{~T}^{3}$

where $\mathrm{S}_{\mathrm{v}}$ in $\mathrm{kJ} /\left(\mathrm{kg}^{\circ} \mathrm{C}\right)$ and $\mathrm{T}$ in ${ }^{\circ} \mathrm{C}$.

\section{References}

[1] A.Seamonds, International Desalination Association (IDA): IDA Desalination Yearbook 2016-2017, USA: Topsfield, M.A., 2016. Available from: http://idadesal.org/wp-content/.

[2] H.T. El-Dessouky, H.M. Ettouney, Fundamentals of Salt Water Desalination, Elsevier, 2002.

[3] I. S. Al-Mutaz, I .Wazeer, Development of a steady-state mathematical model for MEETVC desalination plants, Desalination 351 (2014) 9-18.

[4] A.O. Bin Amer, Second law and sensitivity analysis of large ME-TVC desalination units, Desalin. Water Treat. 53 (2015) 1234-1245.

[5]J.H. Lienhard V, In: H. A. Arafat, Desalination Sustainability A Techincal, Socioeconomic, and Environmental Approach, Elsevier Publishing, 2017, pp. 127-206.

[6] H. Al-Fulaij, A. Cipollina, D. Bogle, H. Ettouney, Steady state and dynamic models of multistage flash desalination: A review, Desalin. Water Treat. 13 (2010) 42-52. 
[7] S. N. Malik, P.A. Bahri, L.T.T. Vu, Steady state optimization of design and operation of desalination systems using Aspen Custom Modeler, Comput. Chem. Eng. 91 (2016) 247-256.

[8] S. Azimibavil, A. J. Dehkordi, Dynamic simulation of a Multi-Effect Distillation (MED) process, Desalination 392 (2016) 91-101.

[9]M. Khamis Mansour, Hassan E.S. Fath, Numerical simulation of flashing process in MSF flash chamber, Desalin. Water Treat. 1 (2012) 1-13.

[10]F. Alamolhodaa, R. KouhiKamalib, M. Asgari, Parametric simulation of MED-TVC units in operation, Desalin. Water Treat. 57 (2015) 1-14.

[11]S. E. Shakib, M. Amidpour, C. Aghanajafi, A new approach for process optimization of a METVC desalination system, Desalin. Water Treat. 37 (2012) 84-96.

[12] K. H. Mistry, M. A. Antar, J.H. Lienhard V, An improved model for multiple effect distillation, Desalin. Water Treat. 51 (2013) 807-821.

[13]R. Kouhikamali, A. Samami Kojidi , M. Asgari, F. Alamolhoda, The effect of condensation and evaporation pressure drop on specific heat transfer surface area and energy consumption in MED-TVC plants, Desalin. Water Treat. 46 (2012) 68-74.

[14]R. Kouhikamali, Z. FallahRamezani, M. Asgari, Investigation of thermo-hydraulic design aspects in optimization of MED plants, Desalin. Water Treat. 51 (2013) 5501-5508.

[15]I. S. Al-Mutaz, I. Wazeer, Optimization of location of thermo-compressor suction in MEDTVC desalination plants, Desalin. Water Treat. 57 (2016) 1-15.

[16] T. H. Dahdah, A. Mitsos, Structural optimization of seawater desalination: I. A flexible superstructure and novel MED-MSF configurations, Desalination 344 (2014) 252-265.

[17]T. H. Dahdah, A. Mitsos, Structural optimization of seawater desalination: II novel MEDMSF-TVC configurations, Desalination 344 (2014) 219-227 
[18] M. Skiborowski, A. Mhamdi, K. Kraemer, W. Marquardt, Model-based structural optimization of seawater desalination plants, Desalination 292 (2012) 30-44.

[19] H. Sayyaadi, A. Saffari, Thermoeconomic optimization of multi effect distillation desalination systems, Appl. Energy 87 (2010) 1122 -1133.

[20] A. Piacentino, Application of advanced thermodynamics, thermoeconomics and exergy costing to a Multiple Effect Distillation plant: In-depth analysis of cost formation process, Desalination 371 (2015) 88-103.

[21] M.S.Tanvir, I.M. Mujtaba, Optimisation of design and operation of MSF desalination process using MINLP technique in gPROMS, Desalination 222 (2008) 419-430.

[22] P. Druetta, P. Aguirre, S. Mussati, Minimizing the total cost of multi effect evaporation systems for seawater desalination, Desalination 344 (2014) 431-445.

[23] I.J. Esfahani, A. Ataei, V.K. Shetty, T. Oh, J. H. Park, C. Yoo, Modeling and genetic algorithm-based multi-objective optimization of the MED-TVC desalination system, Desalination 292 (2012) 87-104.

[24]M.H. Khademi, M.R. Rahimpour, A. Jahanmiri, Simulation and optimization of a six-effect evaporator in a desalination process, Chemical Engineering and Processing: Process Intensification 48 (2009) 339-347.

[25]M.A. Darwish and A.A. El-Hadik, The multi-effect boiling desalting system and its comparison with the multi-stage flash system, Desalination, 60 (1986) 251-265.

[26]R.B.Power, Steam Jet Ejectors for the Process Industries, McGraw-Hill, New York, 1994.

[27]A.K. Coker, Ludwig's Applied Process Design for Chemical and Petrochemical Plants, Fourth Edition, Elsevier, USA, 2007.

[28]R. Turton, R.C. Bailie, W.B. Whiting, Analysis, synthesis, and design of chemical processes, Fourth Edition, Prentice Hall, New York, NY, 2012.

[29]S. Al-Hengaria, W. ElMoudira, M.A. El-Bousiffi, Economic assessment of thermal desalination processes, Desalin. Water Treat. 55 (2015) 2423-2436.

[30]Y. Zhou, R.S.J. Tol, Evaluating the costs of desalination and water transport, Water Resour. Res. 41 (2005) W03003:1-10.

[31]V.C. Onishi, A. Carrero-Parreño, J.A. Reyes-Labarta, R. Ruiz-Femenia, R. Salcedo-Díaz, E.S. Fraga et al., Shale gas flowback water desalination: Single vs multiple-effect evaporation with vapor recompression cycle and thermal integration, Desalination 404 (2017) 230-248. 
[32]J.R. Couper, W.C. Penney, J.R. Fair, S.M. Walas, Chemical process equipment, selection and desing, Second Edition, Elsevier , USA, 2010.

[33]Optimization Toolbox User's Guide, the Math Works, Available online: http://www.mathworks.com, 2017.

[34]A. Messac, Optimization in Practice with MATLAB for Engineering Students and Professionals, Cambridge University Press, USA, 2015.

[35]A.O. Bin Amer, Development and optimization of ME-TVC desalination system, Desalination 294 (2009) 1315-1331.

[36]E.Gencer, R. Agrawal, Strategy to synthesize integrated solar energy coproduction processes with optimal process intensification. Case study: Efficient solar thermal hydrogen production, Comput. Chem. Eng. 105 (2017) 328-347.

[37]M.A.Navarro-Amoros, R. Ruiz-Femenia, J.A. Cabellero, Integration of modular process simulators under the Generalized Disjunctive Programming framework for the structural flowsheet optimization, Comput. Chem. Eng. 67 (2014) 13-25.

[38]Y. Li, X. Huang, H. Peng, X. Ling, S. Tu, Simulation and optimization of humidificationdehumidification evaporation system, Energy 145 (2018) 128-140.

[39]H.T. El-Dessouky, H.M. Ettouney, F. Mandani, Performance of parallel feed multiple effect evaporation system for seawater desalination, Appl. Therm. Eng. 20 (2000) 1679-1706.

[40]M.T. Mazini, A. Yazdizadeh, M.H. Ramezani, Dynamic modeling of multi-effect desalination with thermal vapor compressor plant, Desalination 353 (2014) 98-108. 